The development of a safety and quality culture assessment tool from a longitudinal, mixed method research journey.

\begin{tabular}{|r|l|}
\hline Journal: & Worldwide Hospitality and Tourism Themes \\
\hline Manuscript ID & WHATT-02-2018-0006 \\
\hline Manuscript Type: & Article \\
\hline Keywords: & $\begin{array}{l}\text { Food safety, Quality, Culture Excellence, Behaviour change, Psychology, } \\
\text { Organisation }\end{array}$ \\
\hline \multicolumn{2}{|c}{}
\end{tabular}




\section{The development of a safety and quality culture assessment tool from a longitudinal, mixed method research journey.}

\section{Introduction}

Organisational culture is now widely seen as one of the most important and valuable factors in organisational success across a wide variety of business sectors. Reports by the Association of Chartered Certified Accountants (ACCA), the European Social Research Council (ESRC), the Financial Reporting Council (FRC) and the Chartered Institute of Personnel and Development (CIPD), in the wake of the global financial crisis, have focused on the role of culture within organisations (ACCA, 2014; CIPD, 2016; FRC, 2016). These reports identify human behaviour as central to organisations and culture as the key to understanding and affecting change in human behaviour within organisations (ACCA, 2014).

Interest in culture comes with a recognition that even the most sophisticated policies and procedures do not guarantee compliance; it is people that are central to what happens within an organisation (ACCA, 2014). Organisations have a responsibility to understand behaviour and to challenge it where they find misalignment with values (FRC, 2016). The CIPD recommends that organisations demonstrate accountability and ownership in relation to culture (CIPD, 2016). The reports mentioned above all recommend that organisations measure culture, and the CIPD describes culture as one of the most difficult attributes of an organisation to describe and measure 'but also one of the most important and valuable.' (CIPD, 2016, pg. 5).

Developing frameworks and tools to assess behaviour and culture is seen as an effective approach (FRC, 2016, pg.13). There is recognition that the measurement of culture should be both quantitative and qualitative (CIPD, 2016), and that because there is no one correct way of measuring culture, the solution depends on the context (ACCA, 2014; Jung et al., 2009). The challenge is therefore to identify how best to measure culture within a particular context, and hence the need to develop specific tools for their specific purpose. In this paper the context is food safety and quality, and the purpose is organisational measurement and improvement.

Food safety and quality culture is a vast topic; it involves the psychological, technical and managerial (Taylor, 2011), as well as the visible and invisible (Schein, 2010), the stable and dynamic (Denison, 2012). Food safety culture in particular is a sensitive topic with its implications of hygiene and concern for consumer safety (Taylor, 2007). It is therefore a challenging task to capture the dimensions of food safety and quality culture, and even more so to develop a valid, reliable and practical tool to assess them.

The importance of culture in the food industry and the most recent academic literature on food safety culture are discussed via an academic literature review in paper one of this issue of Worldwide Hospitality and Tourism Themes (Manning, 2018a), and via industry viewpoint in paper seven (Emond, 2018). Furthermore, the growing importance of culture in relation to verifying that food safety standards exist even when an auditor or inspector are not present is discussed in an academic literature review in paper two (Manning, 2018b), and through food inspector viewpoints in paper eight (Nayak, 2018). 
This paper provides an overview of the academic underpinning of the Culture Excellence assessment tool and the conceptual model of safety and quality culture that it was designed to measure. It details a 16-year research journey and presents the overarching themes of the model and associated assessment tool with illustrative qualitative quotations. This sets the scene for paper four of this journal in which quantitative analysis of the data generated from the assessment tool highlights cultural patterns and trends from the food industry (Taylor \& Budworth, 2018). Two individual company case studies from within the hospitality sector are subsequently explored in detail in papers five and six (Caccamo et al., 2018; Nouaimeh et al., 2018).

\section{The Culture Excellence assessment tool}

The Culture Excellence assessment tool is an online food safety and quality survey currently used by hundreds of small, medium and large businesses in hospitality, retail and manufacturing sectors across thousands of locations in 19 countries. It generates core quantitative data on 20 dimensions of culture within 4 categories (see Table 1 ) as well as supporting quantitative data on perceptions and priorities, and qualitative data on experiences and opinions. After the survey is completed, companies can access the data through an online platform which presents a wide variety of data views including internal comparisons and benchmarking against their industry sector, all of which can be filtered by role, site, department or any other demographic determined as valuable.

In 2015 the assessment tool was adopted by Campden BRI and was offered as a service to their members, including pre and post survey workshops, survey customisation, and support services throughout the year. In 2016 a version of the Culture Excellence assessment tool focused solely on food safety was adopted by BRC Global Standards (BRC) as a Voluntary Module to add to the information gathered during third party audits, alongside additional auditor observations of factors that impact on food safety culture (BRC, 2017).

\section{The research and development journey}

The content of the Culture Excellence model and the associated assessment tool is the result of over 16 years of research and development, starting with qualitative research which brought depth and discovery, and using it to create an assessment tool that could produce quantitative and qualitative data for a much larger number of companies (see Table 2). At the start of the research process the main question was 'why don't people adhere to food safety management standards?', and over time this question evolved into an examination, modelling and assessment of food safety and quality culture.

\section{An iterative mixed method approach}

The research and development process for the model and associated assessment tool was iterative in nature, with the research design responding to findings as they emerged as well as new publications, industry developments and concerns. As defined by Srivastava et al. (2009, pg. 77): 'The role of iteration, not as a repetitive mechanical task but as a deeply reflexive process, is key to sparking insight and developing meaning. Reflexive iteration is at the heart of visiting and revisiting the data and connecting them with emerging insights, progressively leading to refined focus and understandings'. It is this iterative approach that kept the research meaningful and relevant. 
The inclusion of both qualitative and quantitative methods on this research and development journey has also been an essential component of the process. The benefits of using qualitative and quantitative research together to build and then test theory are well established and particularly suited to newer research fields (Eisenhardt 1989; Eisenhardt and Graebner 2007). The benefits relate to the distinction between theory building and theory testing described as inductive and deductive research, and the use of small or large groups of participants. Figure 1 illustrates the relationship Eisenhardt describes. Furthermore, each type of method brings inherent advantages and disadvantages (HesseBiber, 2010), and it has only been through their integration that advantages from both could be accessed.

The major benefits of qualitative research are depth, discovery and the resultant richness of data produced. An example scenario from the second and third stages of the research is onsite visits to food businesses (from small restaurants to large factories), with observation of the sites and detailed note taking, multiple in-depth interviews of up to an hour for each, word-for-word transcription, detailed theme analysis, and the integration of what was seen and translated into a report. A single business location could take multiple days to assess, confining the research to a smaller sample. Theory emerges from this type of research, though it cannot be generalised across a larger population.

The major benefits of quantitative research are breadth, and the resultant ability to generalise more widely from the data gathered. Compared to the hundreds of in-depth studies conducted during Stages 1, 2 and 3 combined, there were tens of thousands of industry responses to the Culture Excellence survey during the first few years of Stage 4. Paper 4 in this themed journal edition demonstrates how this type of data can be used to identify broader industry patterns and their statistical significance (Taylor \& Budworth, 2018).

The key to the use of both methods in this research and development process was to start with in-depth qualitative research to generate themes and content, and then use this in the creation of a quantitative assessment tool. This approach is supported within the literature, for example Yauch and Steudel (2003) argue that cultural exploration should start with a period of qualitative assessment, using insights gained to progress to utilisation of a quantitative assessment tool. The qualitative process was discovery-based, using narrative interview questions that did not impart pre-conceived concepts for companies to agree or disagree with, but rather to learn directly from them what the most important issues were (Taylor, 2007). In Stage 2 and 3 the research also included semi-structured observation and document review checklists, providing a structure based on a typical food safety audit yet also enabling the researcher to identify new or unexpected issues. Findings from these stages were then investigated in the context of the literature to validate their relevance and explore them in more detail. The quantitative stage included items that emerged directly from the qualitative stage, cross checked with the broader literature and expert review. Furthermore, the quantitative assessment tool was further supplemented by open questions and follow-on discussion or observation within the company, allowing further refinement of the original themes and content. 


\section{Criteria for inclusion}

The latest version of the Culture Excellence model frames the broad and complex topic of safety and quality culture in a simple structure of 4 categories and 20 dimensions (see Table 1). Continually refined and enhanced over many years of iterative research, this latest version brings together all data gathered to date as well as concurrent developments in industry and the literature.

The main criteria for inclusion in the model were:

1. The theme was discovered inductively from qualitative research via open questions or observations; it appeared in multiple sets of data and was not introduced by the researcher. 2. The theme could be subsequently validated and explored within credible literature on food safety, quality, psychology, management and / or organisational culture.

3. The theme was approved by an expert panel.

The same criteria were applied to the individual questions that were created to assess each of the dimensions of the model in the online assessment tool. Additional requirements for these questions (including clarity, context and facilitation of honest responses) are described in the next paper in this themed journal edition (Taylor \& Budworth, 2018).

\section{Research lead and expert panel}

The research process was led by Dr Joanne Taylor, a qualified psychologist (specialising in qualitative research) with post-graduate qualifications in HACCP, Teaching and Research, a $\mathrm{PhD}$ in the psychological assessment of food safety standards, and many years of experience teaching MSc modules in Organisational Culture, HACCP and research methods, as well as working with government and industry to promote food safety standards in multiple countries. The expert panel who supported the process includes technical experts, experienced industry professionals, academics from the University of Salford, and representatives from Campden BRI and BRC.

\section{Research themes: categories and dimensions of culture}

The themes that emerged from the research process created and refined the structure of the Culture Excellence model, resulting in the 4 categories and 20 dimensions presented in Table 1. Furthermore, the specific topics and issues raised within each theme formed the basis of the questions that were created for the online assessment tool. Each of the 20 dimensions within the model will be explained below, along with a small number of illustrative qualitative quotations gathered from the research journey to bring them to life. Quotations are left in their original format with spelling corrections and minor grammatical corrections where necessary.

Further examples and more detailed descriptions of earlier stages of the research process can be found in earlier publications (see Table 2), as well as special themed issues of the International Journal of Contemporary Hospitality Management (IJCHM, 2008) and Worldwide Hospitality and Tourism Themes (WHATT, 2011; WHATT, 2015). 
People: Empowerment, Reward, Training, Communication and Teamwork

Initially described using the psychological concept of self-efficacy (Bandura, 1977), the empowerment theme emerged from the first stage of the research (e.g. Gilling et al., 2001; Taylor, 2007) and was continually identified.

She did know how things should be done but she didn't have the confidence to do it without constantly asking for reassurance. (Café owner-manager, interview, 2003)

The guys are confident to speak up on health and safety, they'll call us out if we come onto the floor without the right gear on, but food safety, like, well, handwashing, I don't think so! (laughs). (Factory manager, interview, 2014)

A simple definition of empowerment is having the authority to do what is required. In food safety and quality this requires having the confidence and ownership to undertake action when required for food safety, and being sufficiently trusted by managers. Indeed, a metaanalysis of academic studies showed that 'psychological empowerment is in turn positively associated with a broad range of employee outcomes, including job satisfaction, organisational commitment, and task and contextual performance, and is negatively associated with employee strain and turnover intentions' (Seibert, 2011). Furthermore, Denison (2012) includes 'empowerment' as one of 12 dimensions within his model of organisational culture, and a broader analysis of 48 organisational culture assessment instruments identified 'employee participation', 'employee development' and 'trust' as three of the 26 prominent dimensions addressed (Jung et al. 2009).

The reward theme was initially described using the psychological term of reinforcement, a well-established concept developed by leading psychologists in the early $20^{\text {th }}$ Century (e.g. Pavlov, 1927, Skinner, 1933 and Thorndike, 1911). This too emerged from the earliest stages of the research and was continually identified.

At the end of the day you can't get annoyed with food safety... [But] it annoys you when people down the road are similar and do the same job you're doing, and getting the same reward you're getting, and it's obviously not as good. (Restaurant owner-manager, interview, 2003)

We are not praised enough by our Shift Managers for the work that we do but they are very quick to criticise us for any poor work that we do and that for me is unacceptable! (Factory operator, survey, 2015).

The company could look at a more regular incentive scheme... this would boost morale. (Catering supervisor, survey, 2016).

Within the food industry, in businesses of all types and sizes, the use of rewards and incentives is vital in shaping and managing correct food safety behaviours, and also retaining employees. At a broader level the business itself will be more motivated to comply with food safety standards if they see an incentive or reward (e.g. higher audit / inspection scores, increased business), and the concept of consequences and food safety behaviour is described in detail by Yiannas (2009) in his textbook on food safety culture. In organisational 
literature Jung et al. (2009) identify reward as a prominent dimension, and Schein (2010) identifies 'how leaders allocate rewards and status' and 'how leaders recruit, select, promote, and excommunicate' as two of his six primary embedding mechanisms for culture.

The Culture Excellence Model is separated into 20 themes to create a structure of the many separate elements that contribute to it, yet they are all interconnected. Reward and empowerment, for example, go hand in hand in creating a culture of openness and preventing one of blame and fear:

Employees are afraid sometimes to talk about or bring the issues to their supervisors. Employees should be rewarded, encouraged to speak about the issues. (Factory supervisor, survey, 2015).

Training and communication are core methods used by food companies to promote food safety and quality, and they have a range of added benefits to the culture of a company:

Training and communication makes the employees feel appreciated and like they matter. [It] builds team spirit and adds a sense of responsibility and duty. (Catering supervisor, survey, 2016).

Originally referred to in the context of awareness, knowledge and cueing mechanisms, training and communication both emerged in the earliest stages of the research and throughout all stages. In line with research theory (Taylor, 1994), many of the important features that can affect the success or failure of food safety training were raised.

I'll sit and listen to lecturers who are lecturing and really, you know... what they're lecturing about, it's just impractical... and that's... a waste of people's time and money. (Restaurant owner-manager, interview, 2003).

Due to a lack of staff and pressure on managers to get things done the on-the-job training is done by anyone who is available, it at all... the result is a "Chinese whispers" effect that results in many team members not having clear instructions of what to do, how to do it and what is expected of them. (Factory supervisor, survey, 2015).

Reading a PowerPoint in the room does not constitute training. (Factory manager, survey, 2016).

Indeed, training is considered as 'fundamentally important' within the Codex Food Hygiene Basic Texts (CAC, 2009). In organisational literature 'deliberate role modelling, teaching and coaching' is identified as a primary embedding mechanism for culture (Schein, 2010), and 'individual learning' as a prominent dimension within assessment tools (Jung et al., 2009). In food safety literature, Griffith et al. (2010) included 'communication' as one of six core cultural factors influencing food safety performance.

Training and Communication were combined into a single dimension in the first version of the Culture Excellence model. However, a deviation in quantitative scores and extensive 
qualitative comments on communication from the survey and post-survey discussion highlighted them as issues requiring separate scoring.

We only hear things when they surface or on a 'need to know' basis... we need better communication to prevent problems before they occur. (Factory supervisor, survey, 2015).

Communication from senior management is often biased and closed minded to outside opinions or ideas. A 'my way or the highway' mentality. (Catering manager, survey, 2016).

The first stage of the research also highlighted the additional barrier of language and literacy, which has continually emerged due in part to large numbers of workers in the food industry being expatriates. This can make communication more challenging and requires additional levels of effort and support:

I'd say $70 \%$ of food businesses nowadays... they're foreign... and if you send like a sheet of A4 full of type, it's not going to, you know. (Restaurant owner-manager, interview, 2003).

The language barrier here is an accident waiting to happen. (Factory operator, survey, 2016).

Establishing a team is a requirement of Codex HACCP (CAC, 2009), making it a core part of food safety management. Although teamwork was not mentioned very often in the smaller companies researched during stages 1 and 2 (where a HACCP team might consist of a single person, not exist, or not be necessary due to the involvement of everyone), it became a clear issue when conducting research in larger businesses during stages 3 and 4 .

We are supposed to be one team across the company but each shift is trying to outdo each other, this just doesn't work, [it's] causing a lot of problems and until this is resolved we are only going to have problems. (Factory supervisor, survey, 2015).

We need to be one team working for the same goal. (Factory operator, survey, 2016).

Teamwork also emerged frequently in literature on organisational culture (e.g. Denison, 2012), and 'team orientation / team approach' was identified as a prominent dimension by Jung et al. (2009).

Process: systems, management control, co-ordination, consistency and premises

Having a documented system in place is a core requirement of food safety management (CAC, 2009) as well as management systems in other fields related to safety and quality. Issues with documents and records, described as negative guideline factors, were identified in the earliest stages of the research (e.g. Gilling et al., 2001; Taylor, 2007), and repeatedly identified throughout all stages. Indeed, for some business owners, food safety became a 
'bureaucratic nightmare' due to the requirement for documented HACCP systems (Taylor \& Taylor, 2004). It was also identified that more complex or variable businesses had greater problems in implementing management systems.

You'll get some rule book, badly written, that doesn't really apply... and that's going to breed contempt from the people you're trying to impose it on. (Farm owner, interview, 2001).

Food safety is too caught up with documentation... a system should focus on 'doing' not 'writing'. (Restaurant manager, interview, 2003).

In larger businesses and in later interviews, systems were more likely to be established and more readily accepted as part of food safety. However, issues with the burdensome nature of the systems, their quality and practicality, remained a frequently discussed topic.

There is too much paperwork, when a lot could be automated. (Factory supervisor, survey, 2015).

The quality system is complex and time consuming to uphold and maintain. (Factory manager, survey, 2016).

Having many of our specifications and instructions come from central and not from our own local based team members, we get a lot of incorrect or poorly tuned / optimised specifications or instructions (Factory manager, survey, 2016)

Furthermore, in organisational culture literature, Schein (2010) identified 'organisational systems and procedures' as one of the six secondary embedding mechanisms for culture, and in food safety literature Griffith et al. (2010) included 'food safety management systems and style' as one of six core cultural factors influencing food safety.

Management control was identified in the earliest stages of the research, emerging as a frequently discussed requirement and challenge. The importance of management in food safety is well established and indeed the Codex Food Hygiene Basic Texts require that 'effective monitoring and supervision take place' (CAC, 2009). Furthermore, in organisational literature, Schein (2010) includes 'what leaders pay attention to, measure, and control on a regular basis' as a primary embedding mechanism for culture.

I can't remember particular examples I'm afraid... there are changes they [the staff] will make that I won't be aware of, which is, you know, the way things are.

(Restaurant owner-manager, interview, 2003).

Many managers and supervisors are still stuck in the old way of thinking in that they prioritise getting the job done above everything else. (Factory manager, survey, 2015)

Managers seem far removed from other staff, quite aloof. (Factory supervisor, survey, 2016) 
As the research progressed the theme of 'management control' expanded to include a broader range of topics, eventually being split into separate themes. In particular, in the research phase that included larger companies with separate departments and large workforces the issue of co-ordination and consistency came to the forefront. The inclusion of these as separate dimensions was further supported by organisational culture literature.

Effective co-ordination is a key part of business management, and requires communication, positive working relationships, and an understanding of the processes, needs and issues of departments outside one's own. Denison (2012) identifies 'co-ordination and integration' as a core element of organisational culture and Jung et al. (2009) identify 'collaboration / collaborative culture' as a prominent dimension. However, large sites often had issues with inter-departmental co-ordination. Insufficient communication, lack of respect for the technical team, blame, and conflict with priorities were repeatedly raised.

There seems to be a lack of communication between departments - production and sales seem to be battling each other at times rather than working together. (Factory manager, survey, 2015)

Departments are guided to blame the other department instead of working / promoting a team spirit... Money is not made until product goes through the gates regardless of department! (Factory manager, survey, 2016)

Failures are linked to KPIs for separate parts of business not being aligned. We still work as individual units where if it doesn't affect me then I am unwilling to change or listen. (Factory manager, 2016)

Consistency relates to having consistent practices across different people and teams, and also the maintenance of them over time. As well as increasing efficiency, consistency facilitates positive habits and reduces errors. However, it is still a common area for improvement within food businesses.

Before an audit [site name] slows the lines down, cleans the area properly, weighs all ingredients, PPE is checked, managers actually come out [of] the office for a change. (Factory operator, survey, 2016)

The staff turnover, with agency, very changeable, [we are] losing consistency. (Factory manager, survey, 2016)

The drive for consistency is a core component of quality management (ISO, 2015), facilitated in food safety by a systems approach (CAC, 2009), and more recently supported by global auditing schemes incorporating unannounced audit into their scoring systems (BRC, 2015). In the organisational culture literature, while not specifically picked up by Jung et al. (2009), Denison (2012) identifies consistency, not as a dimension, but as a whole quadrant of his culture model. 
The physical premises, facilities and equipment of a business are well established features of food safety (CAC, 2009). From the start of the research, resources were highlighted as a barrier to food safety, and this included time, money, staff, and also the physical premises and facilities.

Space has always been our biggest battle. (Restaurant owner-manager, interview, 2003).

On a busy day we're tripping over each other. (Café owner-manager, interview, 2003).

However, in the first phase of the online survey, questions on the physical premises were kept to a minimum as this was felt to be covered by on-site audit, and they were incorporated within other dimensions. However, when extensive qualitative comments about the physical premises and equipment were captured by the online survey and referenced repeatedly during post-survey discussions, further questions were added to capture the topics in a measurable way, and Premises was introduced as a fifth dimension in the Process category.

I also think we need more space to move around, the site seems so crowded already and it adds risk to the food safety. (Factory manager, survey, 2015)

Some of our premises such as [name of areas] are a thorn in our side due to the old nature of the building structure and associated plant. (Factory supervisor, survey, 2016).

In organisational culture literature, Schein (2010) identifies the 'design of physical space, facades, and buildings' to be a secondary embedding mechanism for culture, and the 'work environment' is identified by Jung et al. (2009) as a prominent dimension of assessment instruments.

Proactivity: External Awareness, Risk Foresight, Innovation and Change, Organisational Learning and Investment

External factors such as suppliers and customers were identified in the earliest stage of the research (e.g. Gilling et al., 2001; Taylor, 2007), and throughout all stages.

We even have a go at our suppliers, when we see them not really doing their bit, so to speak, if not, you know, looking after the product before we get it. (Restaurant owner-manager, interview, 2003).

I get frustrated with narky customers, customers who aren't prepared to wait. (Café owner-manager, interview, 2003).

We have a lack of co-operation from suppliers... and the transport company's disregard for delivery times. (Factory manager, survey, 2016). 
We need to try to get it across 'if you wouldn't buy it, why should anyone else? So make it right, present it right for the customer! (Factory supervisor, survey, 2016).

Supplier management is a crucial aspect of food safety management (CAC, 2009), and having a customer focus is a key element of quality management (ISO, 2015). While suppliers are not included in most organisational culture models, customers do feature. Denison (2012) included 'customer focus' as a core dimension, and Jung et al. (2009) identified 'customer focus' as a prominent dimension of culture assessment instruments.

Risk awareness was identified in the earliest stage of the research, and throughout all stages. In the earlier research phases there was a propensity for interviewees to perceive their business as low risk.

I've never had it [food borne disease] even when I went on holiday I never had anything... I don't think it's a risk. (Restaurant head chef, interview, 2003).

I don't think it's a big risk... I think you probably get a lot more people trying to claim food poisoning rather than anything else. (Bar owner, interview, 2003).

In the later phases the level of risk awareness was more likely to be questioned in other employees, or there was a lack of consistency or focus in where the significant risks existed.

Technical are trying to change people's views on food safety and stopping risks. I think this can be challenging day in day out. (Factory manager, survey, 2015)

The main challenge is when physical, chemical and biological hazards affect the products, then more control points should be applied to prevent foods contamination and to avoid others risks. (Factory supervisor, survey, 2016)

While not addressed specifically in organisational culture literature, the concept of risk is vital to food safety management (CAC, 2009), and Griffith et al. (2010) include 'risk perception' as a core cultural factor influencing food safety.

Food companies are required to change and update their systems and standards in line with global events and updated requirements from national governments, international standards bodies and certification standards. With exponential changes in technology there are also many opportunities for food safety innovation. Innovation and change emerged as core features of stages 3 and 4 of the research journey, particularly in larger companies and groups.

I think [name of department] is the company's biggest weakness. The team there have a poor attitude and are reluctant to change and embrace the vision. (Factory manager, survey, 2015)

Our staff are millennials... we keep developing things on paper but they don't use paper! They want the latest technology. (Catering manager, pre-survey discussion, 2015) 
Innovation and creativeness often takes a back seat due to fear of change or failure. If I hear, 'Well, this is how we always have done', I'm going to puke. (Catering supervisor, survey, 2016)

In organisational literature, Jung et al. (2009) identified both 'change / attitudes to change / creating change' and 'innovation / innovativeness / risk taking' as two of the prominent dimensions within organisational culture assessment instruments.

Organisational learning also emerged as a core feature in stages 3 and 4 of the research journey, particularly where learning was stalled between sites or departments and incidents were being repeated despite systems being in place to prevent them.

It's like, once we've invested in something and started it off, no-one wants to go back. So if it doesn't work properly, we just ignore that and keep going' (Factory manager, interview, 2014).

We have a culture of focusing on placing blame for failures instead of looking for ways to train, mentor and improve. (Catering manager, survey, 2015)

Corrective actions are not completed causing re-occurrences of same issues many times (management reaction not sufficient). (Factory supervisor, survey, 2016).

Food safety management and quality systems require corrective action plans for when things go wrong (CAC, 2009; ISO, 2015) and for these to work effectively they need organisational learning to take place in order to prevent recurrence and allow continual improvement. Moreover, organisational culture literature (e.g. Denison, 2012; Jung et al., 2009) identifies organisational learning as an important element of culture, and Schein (2010) identifies 'how leaders react to critical incidents and organisational crises' as a primary embedding mechanism.

As described earlier, from the start of the research resources were highlighted as a barrier to food safety, and this included financial resources.

It is very expensive to keep up with training... and to follow legislation... I can see a lot of smaller restaurants, smaller businesses, would have problems without a doubt. (Restaurant owner-manager, interview, 2003).

In the first version of the Culture Excellence assessment tool, questions on investment were included within other dimensions rather than being scored separately. However, following extensive qualitative comments in the survey and post-survey discussions, this was separated and scored as a standalone dimension. Indeed, while not referenced specifically in most organisational culture models, 'how leaders allocate resources' was identified by Schein (2010) as a primary embedding mechanism for culture. 
When I ask upper management the status on something I am always told there is no budget... My thought is: How are we supposed to be in compliance if we do not have the money available to fix the problems? (Catering manager, survey, 2016).

We have a very good site here but the constraints that are placed upon us through poor investment is having detrimental effects. (Factory manager, survey, 2016)

The comments were sometimes specific to a single issue or event, but often raised multiple food safety or quality issues linked to budget. When asked to identify potential barriers to food safety and quality culture, one survey respondent simple wrote: 'Budget budget budget'.

Purpose: Vision, Strategy, Values, Targets and Metrics

In the early stages of the research with small and medium sized businesses it was identified that lacking outcome expectancy created a negative impact on safety standards (e.g. Gilling et al., 2001; Taylor, 2007). For example, companies implementing a food safety

management system only because it was required, not due to the expectation that it would make a positive impact on food safety, reduced the effectiveness of their systems. The early research also identified that some companies had a perceived superiority to other companies, sectors or even countries, which prevented them from being willing to improve.

It's just going to higher and higher levels and I'm not really sure what we are aspiring to is actually proving to be any, any better off really in terms of industry. (Restaurant owner-manager, interview, 2003).

I think really my negativity of the whole system is that, its only ever reinforced in this country. You can go to any other country in Europe really, predominantly, and they are probably doing $40 \%$ of our standards... I mean, I think really, that sometimes, we can go a little over the top. (Restaurant owner-manager, interview, 2003).

During stages 3 and 4 when the scope increased to include large businesses, it was identified that businesses with a greater focus on safety and quality would talk specifically about their company goals, plans and vision for food safety and quality, and see having superior standards to their peers as something to continually work towards rather than a cause for annoyance or complacency. Other businesses felt the lack of clear goals, plans or vision negatively affected food safety.

Definitely employee / management commitment to follow our values and work by them every day plays a key role to ensure safe food is delivered on time to our customers every day. (Factory manager, survey, 2015)

We are informed daily in briefings about company standards and goals. (Catering manager, survey, 2016)

There are too many initiatives and processes that conflict or overlap because our processes are not co-ordinated and there is no overarching goal or vision. (Factory manager, survey, 2016) 
It would be good to be engaged by quality teams outside this site to understand the quality strategy at above site level... It would be good to understand what the longterm, aligned plans are. (Factory manager, survey, 2016)

We need clarity of our vision. (Factory manager, survey, 2016)

On-site observations also highlighted posters, written communications, and even videos played to visitors, with formal statements of company vision, goals and / or values that referenced safety and quality. In some cases, these were also mentioned or pointed out by employees directly:

Seeing the company values up on the wall when I entered on my first day, it felt like 'this is the place for me'. (Factory manager, pre-survey discussion, 2015)

There was also increased reference to the use of company metrics, and observation of them being demonstrated on charts and wall displays to motivate greater efforts and compliance. In stage 4 the culture scores themselves were used by several organisations as a key company metric, used in combination with other sources of data for verification and motivational purposes.

In general management literature, the importance of establishing and implementing longterm vision, medium-term strategy and short-term targets is well established, as is the importance of establishing and promoting company metrics and core values. They are also features of organisational culture literature (Denison, 2012; Schein, 2010). Schein for example identifies 'formal statements of organisational philosophy, creeds, and charters' as a secondary embedding mechanism, and 'what leaders pay attention to, measure, and control on a regular basis' as a primary embedding mechanism. The prominent dimensions identified by Jung et al. (2009) include 'goals/goal clarity/goal orientation', 'task(s)/task structure', 'values/core values/espoused values', 'vision', 'orientation performance/performance facilitation/performance measures' and 'results', which can also be seen to reflect the relevance of this set of dimensions.

Moreover, in his textbook on food safety culture, Yiannas (2009) discusses the importance of setting food safety goals and measurements, and describes the lagging and leading indicators (measures) of food safety to include quantitative and qualitative culture surveys. This demonstrates the importance of measuring culture as a leading indicator of food safety, as well as highlighting the importance of multiple forms of measurement.

\section{Conclusion}

This paper provides an overview of the research and development process of the Culture Excellence model and associated assessment tool, an iterative process of in-depth interviews and mixed-method case studies that led to the creation of an online survey, which itself is used for continual improvement of the model and assessment.

The latest version of the model highlights 20 dimensions of food safety and quality culture, structured into 4 categories: People, Process, Purpose and Proactivity. These dimensions 
have been explained in relation to their origins and importance, using examples from key literature and theory in the disciplines of psychology, management, organisational culture, food safety and quality. This is because food safety and quality culture are multi-disciplinary and multi-layered, and require consideration of these many facets.

By starting the research using in-depth qualitative methods, the cultural model was built from the ground up, maximising relevance and context. Culture is highly contextual, and requires a research process that facilitates depth and discovery. However, by using the outputs from the qualitative research to create an assessment tool that gathered quantitative data, the benefits of breadth could also be achieved.

To summarise, the outputs of this research journey are:

1. A specific model of food safety and quality culture with a high level of validity, built from an extensive longitudinal mixed method research design.

2. A high-quality assessment tool that incorporates the in-depth rich data of the qualitative research stages but can provide quantitative results quickly and cost effectively, helping individual businesses to understand their own cultural strengths and weaknesses.

3. Data across a wider population that is more indicative of the industry in general, helping to build further understanding of patterns, trends and issues in food safety and quality culture.

The latter two outputs are expanded upon in the next paper in this themed journal edition (Taylor \& Budworth, 2018).

\section{Limitations}

Although this research journey has spanned multiple sectors and business sizes, it does not purport to be a representative sample of the whole industry. The first 3 stages of the research were based largely in the UK and later UAE, and stage 4 to date has included 19 countries. Further study in a wider range of countries would be necessary to explore the potential impact of national cultural differences (e.g. Hofstede at al., 2010; Taylor, 2011) on the model and assessment tool, and whether these would cause variation between scoring of existing dimensions or create the need for new ones. Furthermore, while it is acknowledged to be of great importance, it is also important for companies to understand that culture 'should not be considered the answer to all organisational problems' (Jung et al., 2009); assessments should be taken for the right reasons at the right time, and when organisations evaluate their food safety and quality standards they should use multiple data sources in conjunction with their culture assessment scores. It is through triangulation of multiple, credible data sources that the most reliable and valid picture of food safety and quality can be gained.

\section{References}

ACCA (2014), Culture and Channelling Corporate Behaviour: Summary of Findings, available at: http://www.accaglobal.com/content/dam/ACCA_Global/Technical/hc/caccb-membersurvey-results.pdf

Bandura, A. (1977), "Self-efficacy: towards a unifying theory of behavioral change", Psychological Review, Vol. 84 No. 2, pp. 191-215. 
BRC (2015), Study of BRC Unannounced Audits, available at:

https://www.brcglobalstandards.com/media/26820/white-paper-study-of-brc-

unannounced-audits.pdf

BRC (2017), Food Safety Culture Module, available at:

https://www.brcglobalstandards.com/brc-global-standards/food-safety/additional-

modules/food-safety-culture-module/

Caccamo, A., Daniel, D., Bulatovic-Schumer, R. U., and Taylor, J.Z. (2018) "Measuring and

improving food safety culture in a 5 star hotel: A case study", Worldwide Hospitality and

Tourism Themes, Vol. 10 No. 2.

CIPD (2016), A duty to care? Evidence of the importance of organisational culture to

effective governance and leadership, available at: https://www.cipd.co.uk/Images/a-duty-

to-care_2016-evidence-of-the-importance-of-organisational-culture-to-effective-

governance-and-leadership_tcm18-14220.pdf

CAC (2009), Food hygiene basic texts ( $4^{\text {th }}$ edition). Codex Alimentarius Commission, World

Health Organisation and Food Agriculture Organisation of the United Nations: Rome.

Denison, D., Hooijberg, R., Lane, N. and Lief, C. (2012), Leading Culture Change in Global

Organisations. Wiley: Jossey-Bass, San Francisco, CA.

Eisenhardt, K. M. (1989), "Building Theories from Case Study Research", Academy of

Management Review, Vol. 14 No.4, pp. 532-550.

Eisenhardt, K. M., \& Graebner, M. E. (2007). "Theory building from cases: Opportunities and challenges. Academy of Management Journal", Vol. 50 No.1, pp. 25-32.

Emond, B. (2018) "The importance of measuring food safety and quality culture: results from a global training survey", Worldwide Hospitality and Tourism Themes, Vol 10, No. 2. FRC (2016), CORPORATE CULTURE AND THE ROLE OF BOARDS: REPORT OF OBSERVATIONS. Financial Reporting Council, available from:

https://www.frc.org.uk/getattachment/3851b9c5-92d3-4695-aeb2-

87c9052dc8c1/Corporate-Culture-and-the-Role-of-Boards-Report-of-Observations.pdf Gilling, S.J., Taylor, E.A., Taylor, J.Z. and Kane, K. (2001), "Successful HACCP implementation in the UK: understanding the barriers through the use of behavioural adherence model",

Journal of Food Protection, Vol. 64 No. 5, pp. 710-715.

Griffith, C., Livesey, K. and Clayton, D. (2010), "Food safety culture: the evolution of an emerging risk factor?", British Food Journal, Vol. 112 No. 4, pp. 426-438.

Hofstede, G., Hofstede, G.J. and Minkov, M. (2010), Cultures and Organizations: Software of the Mind, 3rd ed., McGraw-Hill, New York, NY.

Hesse-Biber, S. (2010), Mixed method research: Merging theory with practice, Guilford

Press, New York, NY.

IJCHM (2008), International Journal of Contemporary Hospitality Management, Vol. 20 No.

5, pp. $480-587$.

ISO (2015), ISO 9001: 2015 (en): Quality management systems - Requirements, International Organisation for Standardisation, available at: http://www.iso.org.

Jung, T., Scott, T., Davies, H.T.O., Bower, P., Whalley, D., McNally, R., Mannion, R. (2009), "Instruments for exploring organisational culture: A review of the literature", Public Administration Review, Vol. 69 No. 6, pp. $1087-1096$.

Lowe, J. and Taylor, J.Z. (2013), "Barriers to HACCP amongst UK farmers and growers: an indepth qualitative study", British Food Journal, Vol. 115 No. 2, pp. 262-278.

Manning, L. (2018a), "The value of food safety culture to the hospitality industry", Worldwide Hospitality and Tourism Themes, Vol. 10 No. 2. 
Manning, L. (2018b), "Triangulation: effective verification of food safety and quality management systems and associated organisational culture", Worldwide Hospitality and Tourism Themes, Vol. 10 No. 2.

Nouaimeh, N., Pazhanthotta, R., Bulatovic-Schumer, R.U., and Taylor, J.Z. (2018), "Measuring and improving food safety culture in a large catering company: A case study", Worldwide Hospitality and Tourism Themes, Vol. 10 No. 2.

Nayak, R. (2018), "Food safety culture - the food inspectors' perspective", Worldwide Hospitality and Tourism Themes, Vol. 10 No. 2.

Pavlov, I.P. (1927), Conditioned Re exes: An Investigation of the Physiological Activity of the Cerebral Cortex, Oxford University Press, London.

Schein, E.H. (2010), Organisational culture and leadership ( $4^{\text {th }}$ edition), Wiley: Jossey-Bass, San Francisco, CA.

Seibert, S.E., Wang, G. and Courtright, S.H. (2011), "Antecedents and Consequences of Psychological and Team Empowerment in Organizations: A Meta-Analytic Review", Journal of Applied Psychology, Vol. 96 No. 5, pp. 981-1003.

Srivastava, P. and Hopwood, N. (2009), "A practical iterative framework for qualitative data analysis", International Journal of Qualitative Methods, Vol.8 No.1, pp. 76-84.

Skinner, B.F. (1933), "Resistance to extinction in the process of conditioning", Journal of General Psychology, Vol. 9 No. 2, pp. 420-429.

Taylor, E.A. (1994), "Food Safety and the Catering Industry", PhD Thesis, University of Bradford, England.

Taylor, E.A. and Taylor, J.Z. (2004), "Investigating HACCP implementation barriers through qualitative psychology", International Journal of Environmental Health, Vol. 14 No. 1, pp. 5363.

Taylor, J.Z. (2007), "Understanding and managing risk: the use of in-depth psychological narrative interviews in the development and evaluation of an innovative new HACCP-based system for catering businesses", PhD Thesis, University of Salford, Manchester.

Taylor, J.Z. (2008), "HACCP for the hospitality industry: a psychological model for success", International Journal of Contemporary Hospitality Management, Vol. 20 No. 5, pp. 508-523. Taylor, J.Z. (2011), "An exploration of food safety culture in a multi-cultural environment: next steps?", Worldwide Hospitality and Tourism Themes, Vol. 3 No. 5, pp. 455-466.

Taylor, J.Z., Akanji, T., Al Shaikh, A., Collison, F. \& Whitehall, P. (2011), "Barriers to HACCP in hospitality: a global problem with global solutions?" Worldwide Hospitality and Tourism Themes, Vol.3 No. 5, pp. 387-401.

Taylor, J.Z., Garat, J.P., Simreen, S. and Sarieddine, G. (2015), "An industry perspective: A new model of Food Safety Culture Excellence and the impact on food safety standards", Worldwide Hospitality and Tourism Themes, Vol. 7 No. 1, pp. $78-89$.

Taylor, J. Z. and Budworth, L. (2018), "Food safety culture: patterns and trends from a quantitative analysis of the Culture Excellence assessment program", Worldwide Hospitality and Tourism Themes, Vol. 10 No. 2.

Azzam, B., Taylor, J. Z. and Bulatovic-Schumer, R.U. (in press), "Mixed method evaluation of food safety management and culture during third party audit". Report for Dubai Municipality, Dubai: UAE. Thorndike, E. (1911), “Animal intelligence (1911)", Thoemmes Press: Classics in Psychology, Vol. 48. 
Yauch, Charlene A., and Harold J. Steudel (2003), "Complementary Use of Qualitative and Quantitative Cultural Assessment Methods", Organizational Research Methods Vol.6 No.4, pp. 465-81.

WHATT (2011), Worldwide Hospitality and Tourism Themes, Vol. 3 No. 5, pp. 385-466. WHATT (2015), Worldwide Hospitality and Tourism Themes, Vol. 7 No. 1, pp. $1-96$. Yiannas, F. (2009), Food Safety Culture Creating a Behavior-Based Food Safety Management System, Springer, New York, NY.

Corresponding author: Dr Joanne Taylor can be contacted at joanne@taylorshannon.com.

\section{Biographies:}

Dr Joanne Zaida Taylor (BSc, PhD, PGCHE) is the lead developer of the Culture Excellence model and assessment tool. She is a qualified psychologist with post-graduate qualifications in HACCP, Teaching and Research, a PhD in the psychological assessment of food safety standards, and many years of experience teaching MSc modules in Organisational Culture, HACCP and research methods. She has worked with government and industry to promote food safety standards in multiple countries, including secondments to the UK FSA. She has published widely in a variety of disciplines related to safety and quality, including the authorship of books, journal articles and training packages, and she was one of the lead developers of SFBB and Menu-Safe, two of the most widely used HACCP systems for catering and food service businesses. 


\section{Paper 3 Tables and Figures}

Table 1. The Culture Excellence Model

\begin{tabular}{|l|l|}
\hline Category & Dimension \\
\hline \multirow{4}{*}{ People } & Empowerment \\
\cline { 2 - 2 } & Reward \\
\cline { 2 - 2 } & Teamwork \\
\cline { 2 - 2 } & Training \\
\cline { 2 - 2 } & Communication \\
\hline Process & Management Control \\
\cline { 2 - 2 } & Co-ordination \\
\cline { 2 - 2 } & Consistency \\
\cline { 2 - 2 } & Systems \\
\cline { 2 - 2 } & Premises \\
\hline Purpose & Vision \\
\cline { 2 - 2 } & Values \\
\cline { 2 - 2 } & Strategy \\
\cline { 2 - 2 } & Targets \\
\cline { 2 - 2 } & Metrics \\
\hline Proactivity & External Awareness \\
\cline { 2 - 2 } & Risk Foresight \\
\cline { 2 - 2 } & Innovation and Change \\
\cline { 2 - 2 } & Organisational Learning \\
\cline { 2 - 2 } & Investment \\
\hline
\end{tabular}

Table 2. Summary of research and development history

\begin{tabular}{|l|l|l|l|}
\hline $\begin{array}{l}\text { Stage 1: In-depth } \\
\text { interviews (UK) }\end{array}$ & $\begin{array}{l}\text { Stage 2: Case } \\
\text { studies (UK) }\end{array}$ & $\begin{array}{l}\text { Stage 3: Case } \\
\text { studies (UK / UAE) }\end{array}$ & $\begin{array}{l}\text { Stage 3: Online } \\
\text { survey (Global) }\end{array}$ \\
\hline $\begin{array}{l}\text { Method: Narrative } \\
\text { structured } \\
\text { interviews, } \\
\text { face-to-face and } \\
\text { telephone. }\end{array}$ & $\begin{array}{l}\text { Method: Mixed } \\
\text { (Interviews, on-site } \\
\text { observations, } \\
\text { document review). }\end{array}$ & $\begin{array}{l}\text { Method: Mixed } \\
\text { (Interviews, on-site } \\
\text { observations, } \\
\text { document review, } \\
\text { pilot survey } \\
\text { questions). }\end{array}$ & $\begin{array}{l}\text { Method: Closed and } \\
\text { open survey } \\
\text { questions, followed } \\
\text { by company } \\
\text { discussions or auditor } \\
\text { observations. }\end{array}$ \\
\hline $\begin{array}{l}\text { Sectors: } \\
\text { Manufacturing and } \\
\text { farming (small and } \\
\text { medium). }\end{array}$ & $\begin{array}{l}\text { Sectors: Catering } \\
\text { and food service } \\
\text { (small). }\end{array}$ & $\begin{array}{l}\text { Sectors: } \\
\text { Manufacturing, } \\
\text { catering and food } \\
\text { service (all sizes). }\end{array}$ & $\begin{array}{l}\text { Sectors: } \\
\text { canufacturing, } \\
\text { service, retail, } \\
\text { farming (all sizes). }\end{array}$ \\
\hline $\begin{array}{l}\text { 1999 onwards } \\
\text { Gilling et al. (2001); } \\
\begin{array}{l}\text { Taylor \& Taylor } \\
\text { (2004); Lowe \& } \\
\text { Taylor (2013). }\end{array}\end{array}$ & $\begin{array}{l}\text { Taylor (2007; 2008; } \\
\text { 2011); Taylor et al. } \\
\text { (2011). }\end{array}$ & $\begin{array}{l}\text { Taylor et al. (2015); } \\
\text { Azzam et al. (in } \\
\text { press). }\end{array}$ & $\begin{array}{l}\text { Taylor \& Budworth } \\
\text { (2018); Caccamo et } \\
\text { al. (2018); Nouaimeh } \\
\text { et al. (2018). }\end{array}$ \\
\hline
\end{tabular}


Worldwide Hospitality and Tourism Themes

Page 20 of 20

$$
\begin{aligned}
& 1 \\
& 2 \\
& 3 \\
& 4 \\
& 5 \\
& 6 \\
& 7 \\
& 8 \\
& 9 \\
& 10 \\
& 11 \\
& 12 \\
& 13 \\
& 14 \\
& 15 \\
& 16 \\
& 17 \\
& 18 \\
& 19 \\
& 20 \\
& 21 \\
& 22 \\
& 23 \\
& 24 \\
& 25 \\
& 26 \\
& 27 \\
& 28 \\
& 29 \\
& 30 \\
& 31 \\
& 32 \\
& 33 \\
& 34 \\
& 35 \\
& 36 \\
& 37 \\
& 38 \\
& 39 \\
& 40 \\
& 41 \\
& 42 \\
& 43 \\
& 44 \\
& 45 \\
& 46 \\
& 47 \\
& 48 \\
& 49 \\
& 50 \\
& 51 \\
& 52 \\
& 53 \\
& 54 \\
& 55 \\
& 56 \\
& 57 \\
& 58 \\
& 59 \\
& 60
\end{aligned}
$$

Figure 1. The complimentary use of inductive and deductive research

inductive

research builds theory (small sample) deductive

research tests

theory (large

sample) 